\title{
ESTÁGIO SUPERVISIONADO IV: o uso das tecnologias digitais na educação especial
}

\author{
Fábio Rolvander Mendes de Sousa ${ }^{1}$, Sábia Belle Conceição de Oliveira ${ }^{2}$, Laercio \\ Pontin Junior $^{3}$
}

${ }^{1}$ Instituto Federal de Educação, Ciência e Tecnologia do Tocantins - (IFTO) - campus Araguatins

${ }^{2}$ Instituto Federal de Educação, Ciência e Tecnologia do Tocantins - (IFTO) - campus Araguatins

${ }^{3}$ Instituto Federal de Educação, Ciência e Tecnologia do Tocantins - (IFTO) - campus Araguatins

\{frolvander, sabiabelle976\}@gmail.com, laercio.juniordifto.edu.br

\begin{abstract}
This article discusses the experiences of supervised internship IV, where the use of digital information and communication technologies was developed as methodological resources, aiming to show the feasibility of its use in the multifunctional resource room, which is directed to students with special educational needs (SEN). During the observation period it was seen that the students did not have mastery with such technologies, in that the work was based on inserting the students in the technological world showing ways of teaching using diverse digital technologies. It was verified the increase in the knowledge of some technological tools besides the practice with such tools. It can be said that the use of digital technologies becomes feasible by broadening the scope of knowledge of the student with SEN, making new doors open.
\end{abstract}

Resumo. Este artigo discorre sobre as experiências vivenciadas no estágio supervisionado $I V$, onde foi desenvolvido o uso das tecnologias digitais de informação e comunicação como recursos metodológicos, com o intuito de mostrar a viabilidade do seu uso na sala de recursos multifuncionais, que é direcionada para alunos com necessidades educacionais especiais (NEE). Durante o período de observação foi visto que os alunos não tinham domínio com tais tecnologias, nisso o trabalho se baseou em inserir os alunos no mundo tecnológico mostrando formas de ensinar utilizando tecnologias digitais diversas. Foi verificado o aumento no conhecimento de algumas ferramentas tecnológicas além da prática com tais ferramentas. Pode-se afirmar que se torna viável o uso das tecnologias digitais ampliando o âmbito de conhecimento do aluno com NEE, fazendo com que novas portas se abram.

\section{Introdução}

Este artigo apresenta as atividades realizadas durante o Estágio Supervisionado IV (ESIV). O ESIV é dividido em três etapas - observação, planejamento e regência - com 
duração total de 100 horas, o mesmo foi realizado com os alunos do ensino fundamental I, na Sala de Recursos Multifuncional (SRM) de uma escola pública de Augustinópolis TO.

Em algumas escolas é possível encontrar as SRM, local utilizado para a realização de atendimentos especializados. As SRM são esquipadas com materiais didáticos, equipamentos de acessibilidade específicos, de forma a melhorar $o$ atendimento dos alunos que necessitam de acompanhamento diferenciado. $\mathrm{Na}$ escola campo de estágio existem 12 alunos que são atendidos na sala de recursos, todos com necessidades educacionais especiais.

A inclusão de pessoas com alguma deficiência, seja ela educacional ou não, fazse mostrar que todas essas pessoas têm direito de usar das condições de vida, da forma comum ou não, sendo na sociedade em que vive. (BATISTA, 2004, P. 101). Educação Especial é uma educação organizada para atender alunos com determinadas necessidades especiais, sendo atrelada ao ensino comum.

Durante a observação na sala de recursos multifuncionais, foi verificado que há um escasso uso das tecnologias digitais no ensino dos alunos com Necessidades Educacionais Especiais (NEE). Tendo em vista essa deficiência, como as tecnologias digitais podem ser úteis no processo de ensino e aprendizagem de alunos com necessidades educacionais especiais?

Desse modo, o objetivo do presente artigo é fazer um relato das atividades desenvolvidas durante o ESIV, que promoveu o ensino e aprendizagem dos alunos com necessidades educacionais especiais através do uso das tecnologias digitais, e demonstrar a aplicabilidade de jogos lúdicos na educação especial.

A utilização de tecnologias na educação vem aumentando a cada dia. A busca pela informação está cada vez maior e as ferramentas para se ter tais informações estão mais acessíveis para a sociedade. Nas escolas o uso do computador e de outras TDIC's (Tecnologias Digitais da Informação e Comunicação) vem evoluindo junto com as necessidades dos educandos e dos educadores.

De acordo com Teske (2007) "as novas tecnologias aplicadas à educação surgem para impulsionar e fomentar o acesso amplo, pelo menos em tese, a informação". Deste modo, percebe-se a importância da utilização das TDIC's como forma de tecnologia assistiva no intuito de auxiliar no processo de ensino aprendizado dos alunos da SRM.

\section{Procedimentos Metodológicos}

Durante a regência foram utilizadas as Tecnologias Digitais de Informação e Comunicação (TDIC's) como ferramentas metodológicas no ensino de conteúdos como o Português e a Matemática, na qual consistiu em ministrar aulas a alunos com necessidades educacionais especiais (NEE) na SRM na forma de incluir tais alunos no ambiente escolar e também na sociedade em geral. As ações foram divididas em três etapas identificadas a seguir.

\subsection{Desenvolvimento de atividades com o computador}

Foram utilizados jogos didáticos sobre a língua portuguesa. Um dos jogos utilizados foi o "Ludo - Primeiros Passos", ilustrado na Figura 1, onde os alunos desenvolveram a 
VII Congresso Brasileiro de Informática na Educação (CBIE 2018)

Anais dos Workshops do VII Congresso Brasileiro de Informática na Educação (WCBIE 2018)

habilidade de leitura, formação de sílabas e frases, formar sílabas e frases e aprenderam conceitos introdutórios de digitação. Este jogo foi aplicado a todos os alunos que participaram do projeto. A etapa 1 foi realizada em 16 aulas, cada aula com duração de 1 hora.

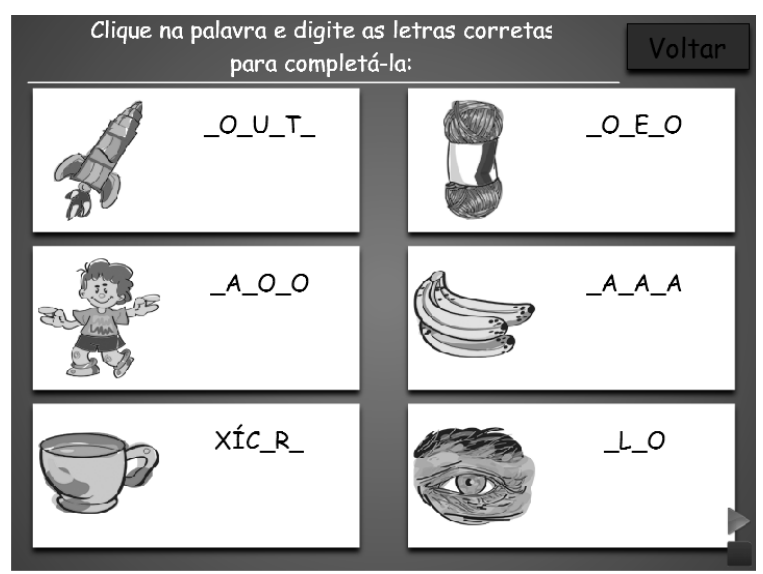

Figura 1: Jogo "Ludo Primeiros Passos"

\subsection{Interpretação de vídeos e utilização do Óculos VR (Virtual Reality)}

Nesta etapa os alunos assistiam um vídeo infantil - vídeos de desenhos animados diversos como a turma da Mônica - e logo após respondiam no computador algumas perguntas referentes ao vídeo assistido. Tais vídeos foram exibidos com óculos VR (Virtual Reality) - mecanismo que pode simular a realidade por meio de mídia virtual. Foi utilizado o VR para mostrar uma tecnologia nova aos alunos e incluir tal tecnologia no ensino, como mostra a Figura 2.

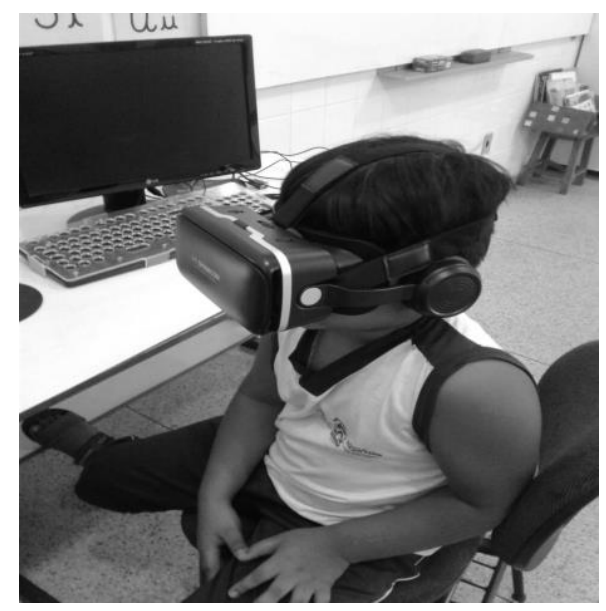

Figura 2: Aluno utilizando Óculos VR duração.

Nesta etapa utilizou-se de 14 aulas para ser concluída, cada aula com 1 hora de

\subsection{Atividades extras utilizando Office Power Point.}

Nesta etapa foi aplicado uma atividade contendo questões onde os alunos ordenaram as letras do alfabeto, digitaram palavras correspondentes a imagem na tela e produziram 
VII Congresso Brasileiro de Informática na Educação (CBIE 2018)

Anais dos Workshops do VII Congresso Brasileiro de Informática na Educação (WCBIE 2018)

textos de própria autoria. Cada aluno teve um tempo para concluir tais questões assim pode-se medir o nível de habilidade e fluência de cada aluno com as ferramentas. Esta etapa foi realizada em 10 aulas.

\section{Resultados e Discussões}

Antes da aplicação das ações percebeu-se que todos os alunos tinham um déficit de conhecimento e prática no computador, isto destaca a importância para se desenvolver algumas habilidades. As habilidades foram trabalhadas ao longo das atividades e constatou-se, de forma direta através das atividades mencionada no item 3.3, que a maioria do alunos conseguiram, através da prática, desenvolver tais habilidades.

Devido as ações executadas pode-se iniciar o processo de inclusão dos alunos com NEE ao mundo das tecnologias, com o projeto os alunos descobriram que é possível utilizar ferramentas como óculos VR e jogos digitais como recurso de ensino, observaram que é possível brincar enquanto aprendem.

\section{Conclusões}

O uso das TDIC's se torna praticável ao se utilizar na forma que se tenha um retorno positivos dos discentes. Foi possível notar que o uso de tecnologias digitais como recurso metodológico direcionado aos alunos com necessidades educacionais especiais é viável e trouxe um bom resultado aos alunos submetidos as atividades.

Este trabalho abre portas para que outros possam complementá-los, podendo fazer um levantamento mais abrangente da eficiência do uso das TDIC's em relação ao ensino tradicional, ainda mais no âmbito da educação especial.

\section{Referências}

BATISTA, Marcus Welby; ENUMO, Sônia Regina Fiorim. Inclusão escolar e deficiência mental: análise da interação social entre companheiros. Estudos de psicologia, 2004, 9.1: 101-111. Disponível em: $<$ http://www.scielo.br/pdf/epsic/v9n1/22386> Acesso em: 15 dez. 17.

GLAT, Rosana; FERNANDES, Edicléa Mascarenhas. Da educação segregada à educação inclusiva: uma breve reflexão sobre os paradigmas educacionais no contexto da educação especial brasileira. Revista Inclusão, 2005, 1.1: 35-39. Disponível em: < $\quad$ https://pt-static.zdn.net/files/df5/ac5f60b62303b5061bfba7c01690e129.pdf $>$ Acesso em: 15 jan. 18.

TESKE, Prof ${ }^{\circ}$ Dr Eduardo Garcia. Novas tecnologias na educação. 2007. Disponível em:

https://scholar.googleusercontent.com/scholar?q=cache:xrn7YLJKRkQJ:scholar.goo gle.com/+Novas + tecnologias + na + educa $\% \mathrm{C} 3 \% \mathrm{~A} 7 \% \mathrm{C} 3 \% \mathrm{~A} 3 \mathrm{o}+$ teske $\&$ hl $=$ ptPT\&as_sdt=0,5>. Acesso em: 14 dez. 17.

ZEDNIK, Herik, et al. "Tecnologias Digitais na Educação: proposta taxonômica para apoio à integração da tecnologia em sala de aula." Anais do Workshop de Informática na Escola. Vol. 20. No. 1. 2014. Disponível em $<$ http://www.brie.org/pub/index.php/wie/article/view/3135/2643> Acesso em: 15 jan. 18. 